\title{
Neighbour identity hardly affects litter-mixture effects on decomposition rates of New Zealand forest species
}

\author{
Bart Hoorens $\cdot$ David Coomes $\cdot$ Rien Aerts
}

Received: 27 May 2008 / Accepted: 24 August 2009 / Published online: 13 September 2009

(C) The Author(s) 2009. This article is published with open access at Springerlink.com

\begin{abstract}
The mass loss of litter mixtures is often different than expected based on the mass loss of the component species. We investigated if the identity of neighbour species affects these litter-mixing effects. To achieve this, we compared decomposition rates in monoculture and in all possible two-species combinations of eight tree species, widely differing in litter chemistry, set out in two contrasting New Zealand forest types. Litter from the mixed-species litter bags was separated into its component species, which allowed us to quantify the importance of litter-mixing effects and neighbour identity, relative to the effects of species identity, litter chemistry and litter incubation environment. Controlling factors on litter decomposition rate decreased in importance in the order: species identity (litter quality) $>>$ forest type $>>$ neighbour species. Species identity had the strongest influence on decomposition rate. Interspecific differences in initial litter lignin concentration explained a large proportion of the interspecific differences in litter decomposition rate. Litter mass loss was higher and litter-mixture effects were stronger on the younger, more
\end{abstract}

Communicated by Stephan Hattenschwiler.

B. Hoorens $\cdot$ R. Aerts $(\bowtie)$

Department of Systems Ecology,

Institute of Ecological Science, VU University Amsterdam,

De Boelelaan 1085, Amsterdam 1081 HV, The Netherlands

e-mail: rien.aerts@falw.vu.nl

D. Coomes

Department of Plant Sciences,

University of Cambridge, Cambridge CB2 3EA, UK

D. Coomes

Landcare Research, PO Box 69,

Lincoln, New Zealand fertile alluvial soils than on the older, less-fertile marine terrace soils. Litter-mixture effects only shifted percentage mass loss within the range of $1.5 \%$. There was no evidence that certain litter mixtures consistently showed interactive effects. Contrary to common theory, adding a relatively fast-decomposing species generally slowed down the decomposition of the slower decomposing species in the mixture. This study shows that: (1) species identity, litter chemistry and forest type are quantitatively the most important drivers of litter decomposition in a New Zealand rain forest; (2) litter-mixture effects-although statistically significant-are far less important and hardly depend on the identity and the chemical characteristics of the neighbour species; (3) additive effects predominate in this ecosystem, so that mass dynamics of the mixtures can be predicted from the monocultures.

Keywords Litter chemistry $\cdot$ Nutrient transfer · Phenolics · Soil fertility

\section{Introduction}

Litter decomposition provides the main source of nutrients for biological activity in almost all terrestrial ecosystems. During the process of litter decomposition, organic macromolecules (i.e. dead plant material) are broken down into nutrients in plant-available form, inorganic forms of $\mathrm{C}$ and nutrients and stable organic matter (Parton et al. 2007). This flux of nutrients dwarfs the supply of available nutrients from mineral weathering in all but the youngest soils (Swift et al. 1979). Therefore, litter decomposition rate is closely linked with important ecosystem attributes such as productivity, plant species composition and food-chain dynamics (Tenney and Waksman 1929; Melillo et al. 1982; 
Grime et al. 1996; Aerts 1999; Cornwell et al. 2008), and an in-depth understanding of the determinants of litter decomposition rate will greatly contribute to understanding the functioning of terrestrial ecosystems.

Litter decomposition rates vary greatly among climatic zones, species and among sites of differing nutrient status that experience similar climatic conditions. Climate has a direct effect on litter decomposition due to the effects of temperature and moisture. However, as a result of the climatic control of soil formation and nutrient cycling climate also has an indirect effect through the climatic impact on litter chemistry (Aerts 1997). Recently, it has been shown that the magnitude of species-driven variation in litter decomposition rates is much larger than previously thought and even greater than climate-driven variation (Cornwell et al. 2008). It is well established that the chemical composition of plant litter is the primary driver of litter decomposition rate at the ecosystem level. In particular, the concentration of mineral nutrients and different types of structural and defence compounds in freshly fallen litter correlate strongly with litter decomposition rate (Cadisch and Giller 1997; Aerts 1997). However, specific chemical characteristics are only proxies for the overall species-driven controls on litter decomposition rates. Therefore, recent studies have shown that species identity has a higher explanatory power for litter decomposition rates than litter chemistry parameters (e.g. Dorrepaal et al. 2005; Cornwell et al. 2008). Incubation environment is the next control on litter decomposition rates as several studies have demonstrated that litter decomposes more rapidly in nutrient-rich habitats (e.g. Ostertag and Hobbie 1999; Hobbie and Vitousek 2000; Dent et al. 2006). One of the ways soil nutrient status affects litter decomposition rate is by affecting the quality of litter inputs into the system through effects on plant species composition and the chemical composition of the litter that is produced. Compared to more fertile soils, infertile soils not only support different plant species with generally lower litter nutrient concentrations, but also the same species have lower litter nutrient concentrations when grown on less fertile soils (Richardson et al. 2005). These litter inputs of different quality affect the decomposer community and subsequently the rate at which litter is broken down. Highquality litter inputs generally favour bacterial-dominated food webs, whereas fungi become relatively more important with decreasing quality of litter inputs. Such fungalbased food webs are more efficient and retentive and thus nutrients become less available (Wardle et al. 2004; Williamson et al. 2005). As a result, a given litter type will generally decompose faster on nutrient-rich sites compared to less fertile sites (Wardle et al. 2004; Dent et al. 2006).

What is less well understood is how litter of one species responds to being mixed with that of other species. Litter decomposition studies have very often dealt with the decomposition of single-species litter, but most terrestrial ecosystems contain multiple species of plants and so the litter layer comprises leaves from a number of species. As a consequence of litter mixing, the decomposition of a given litter type may be influenced by the presence of other litter types. Mixing litter can have no effect (additivity) or either accelerate or decelerate decomposition. In the case that non-additive mixing effects occur, differences between observed and expected mass loss of 20-30\% are not uncommon (Montagnini et al. 1993; Wardle et al. 1997; Anderson and Hetherington 1999; Hoorens et al. 2003; Gartner and Cardon 2004; Hättenschwiler et al. 2005; Ball et al. 2008). Currently, there is consensus about the fact that these interactions are not driven by litter species richness by itself, but by the composition of the litter mixture, i.e. the specific effect that a species has on its 'neighbour' (Hättenschwiler et al. 2005; Ball et al. 2008). However, in most studies the mixtures have not been separated by species and no attempts have been made to quantify these 'neighbour effects', so it is an open question how neighbour identity affects litter decomposition rates in mixtures.

Interaction effects may be caused by chemical interactions between the component litters or by changes in the decomposition micro-environment (Hector et al. 2000; Wardle et al. 2003; Hoorens et al. 2003; Madritch and Cardinale 2007; Schimel and Hättenschwiler 2007; Jonsson and Wardle 2008). Several studies found that litter mixtures decompose faster than expected when the component species differ in their litter nutrient concentration (Wardle et al. 1997; Quested et al. 2002). In this case, the relatively high amounts of nutrients in one of the litter types could aid the decomposition of the other litter in the mixture. These nutrients are supposedly translocated from one litter type to another through diffusion through a water film and/or actively transported through the hyphae of fungi connecting two different litter types (McTiernan et al. 1997). Negative interactions are also possible (e.g. Wardle et al. 1997; Robinson et al. 1999; Hoorens et al. 2003). Such negative interactions may occur if one of the component litter types contains high amounts of secondary compounds, such as phenolics. Phenolics may slow down the decomposition of litter mixtures in several ways. Polyphenolics, such as tannins, form resistant complexes with proteins (Hättenschwiler and Vitousek 2000). Tannins not only complex with digestive fungal extracellular enzymes, but probably also affect the structural and/or enzymic proteins within the hyphae, thus directly inhibiting microbial growth and activity (Schimel et al. 1998). Polyphenols also complex with nutritional proteins, rendering the $\mathrm{N}$ unavailable to decomposer organisms and consequently slow down decomposition (Hättenschwiler and Vitousek 2000). Thus, if one species in a mixture contains large amounts of phenolics, this could slow down the decomposition of the entire litter 
mixture. However, in an earlier study (Hoorens et al. 2003) we found that interactions in litter mixtures are unrelated to differences in litter chemistry (including phenolics) of the component species. In that study, however, we did not separate the decomposed mixtures by species, so we could only evaluate what the overall mass loss was compared to the expected mass loss based on decomposition of single species. The next step to be taken is to investigate how the identity of the neighbour species, which includes its chemical characteristics, affects the decomposition of the component species in the mixtures. This requires separation of the decomposed mixtures into their component species. However, although highly desirable in this type of study (Hättenschwiler et al. 2005), this is hardly done due to the practical difficulties involved.

The aim of this study was twofold: (1) to quantify the relative effects of species identity, litter chemistry, litter incubation environment and neighbour species on litter mass loss rates in mixtures; and (2) to investigate if neighbour identity (through specific litter chemistry) affects the litter mixture effects. To achieve this, we compared decomposition rates in monoculture and in all possible two-species combinations of eight tree species, widely differing in litter chemistry, set out in two contrasting New Zealand forest types that differ enormously in soil $\mathrm{P}$ and in drainage (Mark et al. 1988; Coomes et al. 2005). Litter from the mixed-species litter bags was separated into its component species, which allowed us to quantify the importance of litter-mixing effects and neighbour identity, relative to the effects of species identity, litter chemistry and litter incubation environment. We investigated two-species mixtures only as we were not aiming to investigate the diversity effect, but only the neighbour identity effect.

\section{Materials and methods}

Study site

The study was conducted in Waitutu forest, Fiordland National Park, in the south-west of New Zealand's South Island $\left(46.4^{\circ} \mathrm{S}, 167.2^{\circ} \mathrm{E}\right.$; Fig. 1$)$. The average annual precipitation is high, at around 1,600-2,400 $\mathrm{mm}_{\text {year }}{ }^{-1}$ (Mark et al. 1988), and the area supports lowland temperate rain forest. The average annual temperature is around $10^{\circ} \mathrm{C}$, with mean January and July temperatures of $12^{\circ} \mathrm{C}$ and $5^{\circ} \mathrm{C}$, respectively (Ward 1988). Due to the moderating influence of the nearby ocean, winters are mild with infrequent snow in the lowlands. We placed litterbags in two contrasting forest types: ancient marine terraces created by the uplift of ocean floor, and alluvial sites adjoining two rivers that intersect these older terraces (Coomes et al. 2005). The alluvial soils are sandy loams and clay loams that are replenished with fresh alluvium every few years. They are relatively rich in nutrients, and particularly in plant-available forms of $\mathrm{PO}_{4}{ }^{3-}$ (Coomes et al. 2005). The soil profile consists of a thin $(\sim 2 \mathrm{~mm})$ layer of decomposing litter on the surface beneath which is a well-aerated and structured mineral soil. Details of the soil properties of both forest types are given in Table 1 . The terraces are poorly drained because the slope is shallow and a gravel layer of low permeability lies at between 20 - and $60-\mathrm{cm}$ depth. These soils
Fig. 1 Map of study area in south-western South Island, New Zealand, showing a sequence of marine terraces and alluvial surfaces (adapted from Ward 1988). About 13 marine terraces have been formed by uplift during the Quaternary (of which terraces 2, 3, 4 and 6 are identified), forming a chronosequence dating back about 900 kyears. Streams have dissected the marine terraces and deposited alluvial surfaces; the youngest alluvial surfaces border the rivers shown. Filled circles indicate the position of eight litter incubation sites in the terrace forest type (T1-8), and open circles indicate the locations of eight litter incubation sites in the alluvial forest type (A1-8)

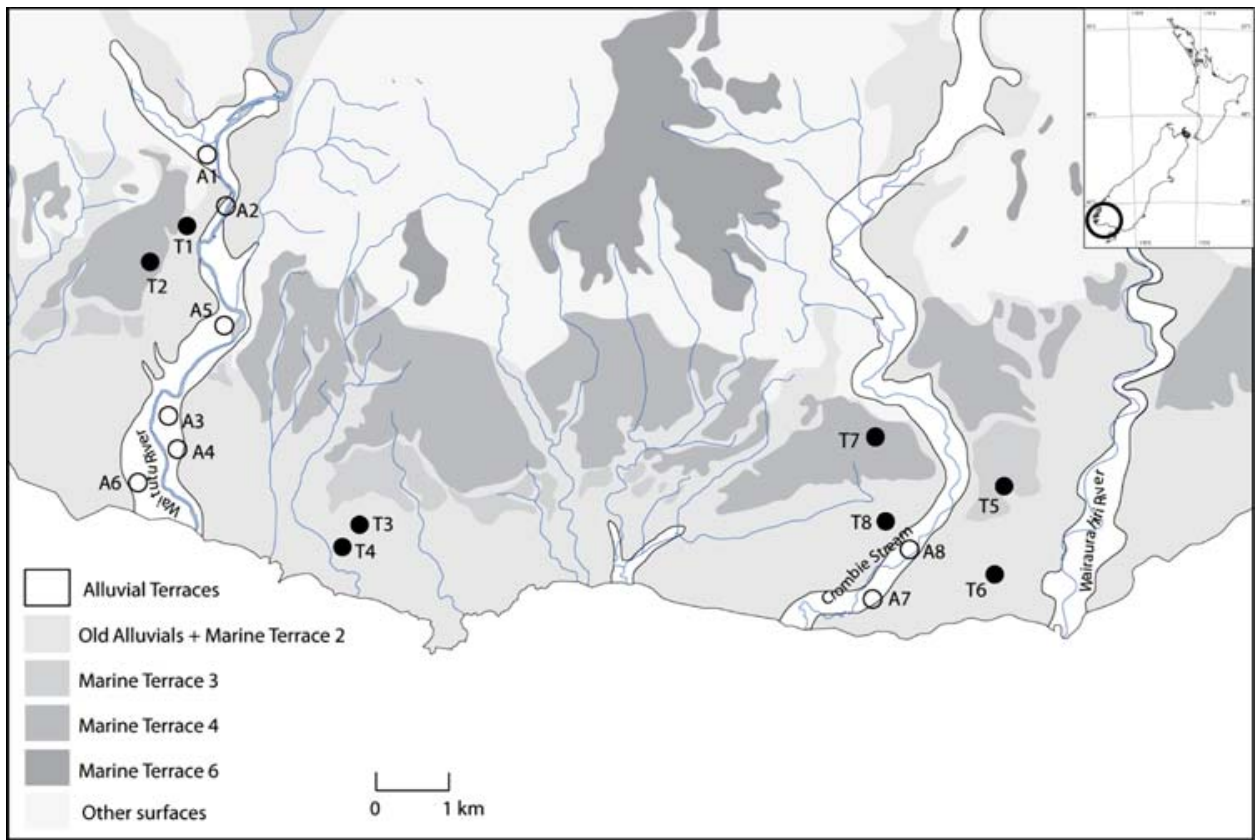


Table 1 Description of soil properties of the two forest types [source: Coomes et al. (2005)]

\begin{tabular}{lcc}
\hline & Alluvial forest & Terrace forest \\
\hline General soil properties & & \\
$\mathrm{pH}$ & $4.92 \pm 0.04$ & $3.91 \pm 0.01$ \\
Total C $\left(\mathrm{g} \mathrm{m}^{-2}\right)$ & $6,563 \pm 249$ & $11,757 \pm 357$ \\
$\mathrm{~F} / \mathrm{H}$ layer depth $(\mathrm{cm})$ & $0.24 \pm 0.24$ & $9.30 \pm 1.61$ \\
Water in F/H layer $\left(\mathrm{g} \mathrm{g}^{-1}\right)$ & $237 \pm 24$ & $412 \pm 15$ \\
$\mathrm{~N}$ & & \\
$\mathrm{~N}$ mineralization $\left(\mathrm{g} \mathrm{m}^{-2}\right)$ & $2.03 \pm 0.33$ & $1.15 \pm 0.10$ \\
Total N $\left(\mathrm{g} \mathrm{m}^{-2}\right)$ & $286 \pm 10$ & $307 \pm 8$ \\
C:N ratio & $24 \pm 1$ & $39 \pm 1$ \\
$\mathrm{P}$ & & \\
Acid-digested P $\left(\mathrm{g} \mathrm{m}^{-2}\right)$ & $48 \pm 1$ & $0.97 \pm 0.01$ \\
Total P $\left(\mathrm{g} \mathrm{m}^{-2}\right)$ & $87 \pm 8$ & $11 \pm 0$ \\
C:P ratio & $75 \pm 24$ & $1,031 \pm 43$ \\
Organic:total P ratio & $0.57 \pm 0.04$ & $0.92 \pm 0.00$ \\
N:P ratio & $5.7 \pm 0.8$ & $28.5 \pm 0.8$ \\
\hline
\end{tabular}

have less plant-available $\mathrm{P}$ and support much slower growth rates than the alluvial soils. The alluvial and terrace forests share many of the same tree species, but differ hugely in composition and structure. In brief, the more fertile alluvial forests are dominated by tall angiosperm trees and contain a diverse assemblage of short angiosperm trees that form a subcanopy. The understory is dominated by tree ferns (Cyathea smithii and Dicksonia squarrosa) and the forest floor is dense with crown ferns (Blechnum discolor). In contrast the less fertile terrace forests are co-dominated by angiosperm and conifer trees, with both fewer subcanopy trees and understory ferns (Mark et al. 1988; Coomes et al. 2005).
Litter decomposition experiment

In December we collected recently fallen leaves from the forest floor of the terrace forest. Litter from the following tree species was collected: Podocarpus hallii, Dacrydium cupressinum (conifers in the Podocarpaceae); Griselinia littoralis, Pseudopanax simplex, Pseudowintera colorata (large-leaved subcanopy angiosperms); Nothofagus menziesii, Metrosideros umbellata, and Weinmannia racemosa (small-leaved canopy angiosperms) all of which are found in both forest types. Freshly fallen litter was collected from a single site (the marine-terrace forest). Litter was initially air dried in the field immediately after collection and further air-dried upon arrival in the lab. A detailed description of the chemical characteristics of these litter types can be found in Table 2.

Litterbags were made from plastic insect screen with \pm 1 -mm mesh size. Each bag was filled with about $1.0 \mathrm{~g}$ of air-dried leaf litter, weighed to the nearest milligram, of either a single species or a 50-50 mixture of each of the 28 possible two-species combinations. We restrained ourselves to two-species mixtures only, as we were interested in compositional effects (neighbour identity) and not in diversity effects. For every species and litter mixture, 32 litterbags were prepared: 8 replicates $\times 2$ forest types $\times 2$ retrieval dates. Subsamples of litter from each species were retained for the determination of initial chemical composition of the litter, as well as determination of air- to oven-dry ratio. For each forest type, litterbags were incubated in eight replicate plots that were several hundred metres apart (Fig. 1). These plots thus contained two sets of litterbags of all single species and mixtures, one set for each of the two retrievals. Litterbags were placed on the forest floor in a random arrangement on top of the litter layer and held in place by metal pins. On the alluvial sites, the plots were

Table 2 Chemical characteristics of the litter of species used in the experiment

\begin{tabular}{|c|c|c|c|c|c|c|c|c|}
\hline Species name & Acronym & $\mathrm{N}\left(\mathrm{mg} \mathrm{g}^{-1}\right)$ & $\mathrm{P}\left(\mathrm{mg} \mathrm{g}^{-1}\right)$ & $\begin{array}{l}\text { Cellulose } \\
(\%)\end{array}$ & Lignin $(\%)$ & $\begin{array}{l}\text { Total } \\
\text { phenols }(\%)\end{array}$ & $\begin{array}{l}\text { Tannins } \\
(\%)\end{array}$ & $\begin{array}{l}\text { Condensed } \\
\text { tannins }(\%)\end{array}$ \\
\hline \multicolumn{9}{|l|}{ Conifers (Podocarpaceae) } \\
\hline Podocarpus hallii & Podhal & 7.7 & 0.390 & 24.0 & 24.6 & 8.8 & 7.0 & 0.7 \\
\hline Dacrydium cupressinum & Daccup & 8.2 & 0.338 & 22.8 & 33.6 & 3.0 & 1.4 & 0.2 \\
\hline \multicolumn{9}{|l|}{ Large-leaved angiosperms } \\
\hline Griselinia littoralis & Grilit & 6.0 & 0.253 & 16.6 & 12.6 & 2.0 & 0.4 & 0.0 \\
\hline Pseudopanax simplex & Psesim & 5.3 & 0.266 & 12.4 & 15.8 & 3.4 & 0.8 & 0.2 \\
\hline Pseudowintera colorata & Psecol & 2.1 & 0.653 & 14.8 & 29.7 & 5.1 & 3.3 & 2.6 \\
\hline \multicolumn{9}{|l|}{ Small-leaved angiosperms } \\
\hline Nothofagus menziesii & Notmen & 7.1 & 0.364 & 20.6 & 26.4 & 7.2 & 5.4 & 2.8 \\
\hline Metrosideros umbellata & Metumb & 3.2 & 0.095 & 18.2 & 15.2 & 35.9 & 31.3 & 5.9 \\
\hline Weinmannia racemosa & Weirac & 5.0 & 0.207 & 16.0 & 19.2 & 38.3 & 34.9 & 7.7 \\
\hline
\end{tabular}

The analyses were performed in triplicate on bulk samples with an analytical error of less than 5\% 
fenced with trawl netting to protect against pig rooting (pigs were common at these fertile alluvial sites). Litterbags were retrieved after 7 and 14 months and initially air-dried in the field immediately after collection, and further airdried upon arrival in the lab. The remaining litter was then cleaned from adhering soil and organic matter by gentle brushing. The contents of mixed-species litterbags were separated into the component species; given the strong morphological and structural differences among the species, which belonged to very different species groups (Table 2), this was relatively easy. Leaf structure remained relatively stable over time and the mass loss of the non-conifers mainly occurred from the tissues in between the veins in the leaves, which made the species recognizable even after 14 months of decomposition. Litter was oven-dried ( $\geq 48 \mathrm{~h}$, $80^{\circ} \mathrm{C}$ ) and weighed.

\section{Chemical analyses}

Concentrations of $\mathrm{C}$ and $\mathrm{N}$ were determined by dry combustion on a Perkin Elmer 2400 CHNS analyser, while concentrations of $\mathrm{P}$ were determined colorimetrically using the ammonium molybdate method, after acid digestion (Murphy and Riley 1962). Cellulose and lignin concentration were determined using the acid-detergent fibre procedure (Rowland and Roberts 1994). Phenolics were extracted using repeated sonication in a $70 \%$ acetone solution. Total phenolics concentration in the litter was determined by means of the Folin-Ciocalteu method (Waterman and Mole 1994) using tannic acid as a standard. After extraction, total phenolics concentration was determined colorimetrically by using the Folin-Ciocalteu reagent and aqueous $\mathrm{NaCO}_{3}^{-}$. Initial litter tannin concentration was measured by adding polyvinylpyrrolidone after extraction to bind tannins. After centrifuging, the supernatant (now only containing, other than tannins, simple phenolics), was analysed with the abovementioned Folin-Ciocalteu method and tannin concentration was calculated. Condensed tannin concentration (\% in dry matter) was expressed as leucocyanidin equivalent after adding butanol- $\mathrm{HCl}$ and ferric reagents after extraction, and measuring absorbance at $550 \mathrm{~nm}$ (Porter et al. 1986; Makkar 1994).

\section{Calculations and statistical analysis}

Litter mass loss, expressed as a percentage of the initial litter dry weight, was calculated for both incubation periods (0-7 and 0-14 months). A small percentage of the litterbags were never recovered $(5.3 \%)$ and these are treated as missing values.

The contents of the mixed-species litterbags were separated into their component species. For each component we recorded its species identity, the identity of the neighbour species and the forest type in which the litterbag had been incubated. ANOVAs were conducted using the linear modelling function $(\mathrm{lm})$ in $\mathrm{R}$ statistics software ( $\mathrm{R}$ foundation 2006). This procedure allowed us to test whether the decomposition of a species was significantly affected by its identity (Species), the forest type in which the litterbag had been incubated (Forest), and the identity of the other species in the mixture (Other species). Separate models were run for the 0- to 7-month and 0- to 14-month incubation periods. The models included all interactions terms involving these factors, as well as a term which incorporated the variability among replicates within each forest type (a blocking term). This approach allowed us to express the relative importance of each factor as its sum of squares as a proportion of the total sum of squares $\left(r^{2}\right)$.

The residuals were approximately normal in distribution, confirming that ANOVA was a suitable approach. We also calculated the percentage litter mass loss for the second period of the incubation (i.e. 7-14 months); however, the residuals of models including this data were found to deviate substantially from a normal distribution, so ANOVAs are not reported here.

It was possible to calculate the effect of species on the rate of decomposition of the other species in the litter bags due to the fact that all species are present both as target species and as 'other' species. First, we calculated the mean \% mass loss after 14 months for each target species in the presence of each other species in the litter bags. These values would be equal for each species if the other species had no effect on decomposition. Next, these means were subtracted from the values observed for each species. The rationale behind this is that if the other species had no effect on the target species, or idiosyncratic effects (accelerating some target species and slowing down others), then the calculated value would be zero. If the species tended to accelerate the decomposition of the target species then the effect would be a greater than zero loss rate, whereas if the species tended to decelerate the decomposition of the target species then the effect would be a less than zero loss rate.

\section{Results}

The average amount of litter loss in the first 7 months was $33 \%$, compared with $18 \%$ of the remaining litter in the following 7 months (Fig. 2a). Therefore, there was an appreciable slowing of decomposition rate over time, even though the first 7 months included the winter months and the latter 7 months included the summer months, in which warmer temperatures should have contributed to faster decomposition rates. After 7 months of incubation, litter mass loss was significantly influenced by just two factors: 


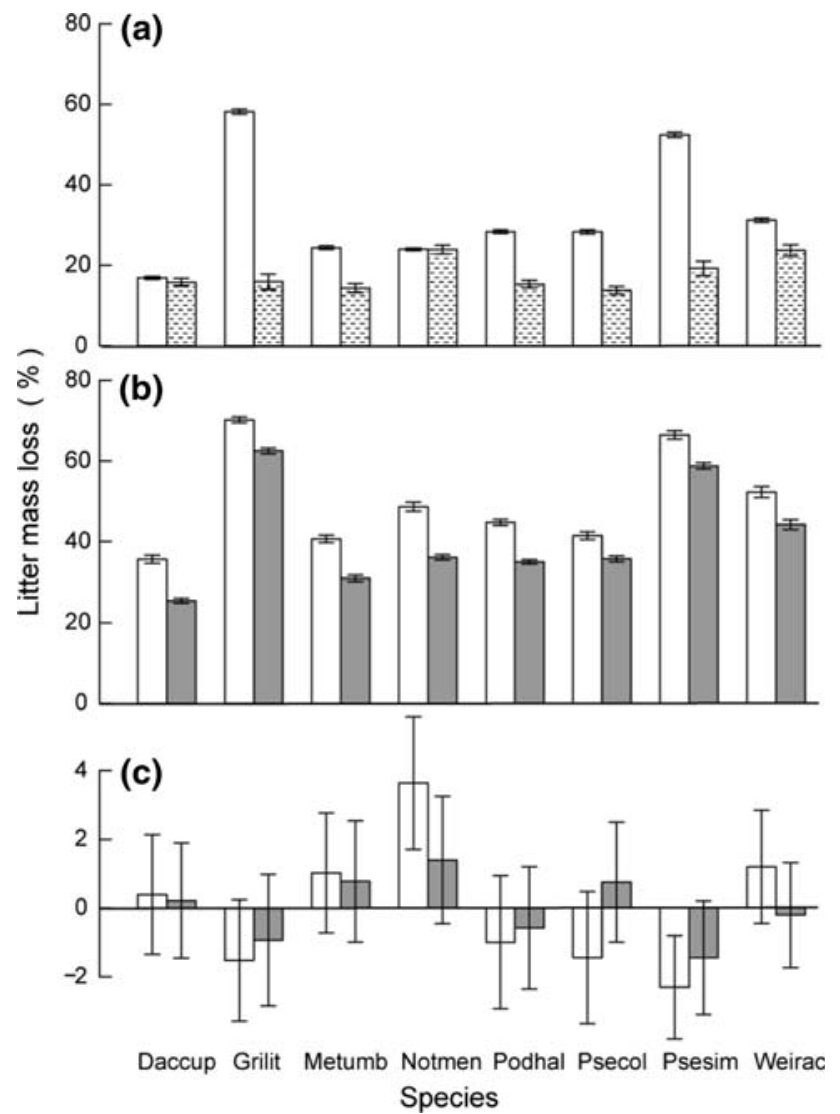

Fig. 2 Average ( \pm 1 SEM) percent mass loss of eight species of New Zealand trees a 0-7 months (open bars) and 7-14 months (dotted bars) after the start of the experiment, b for bags placed in alluvial (open bars) versus terrace (filled bars) forests (after 14 months of decomposition), and $\mathbf{c}$ effects of target species on the rate of decomposition of other species in bag, for alluvial (open bars) and terrace (filled bars) forests (after 14 months of decomposition). See Table 2 for abbreviations of the species names the identity of the species and forest type (both significant at $P<0.001$; Table 3). However, after 14 months of incubation, four factors significantly influenced mass loss: Species, Forest type and the identity of the other species (Other species) in the mixture, and the Species $\times$ Forest interaction (significant at $P<0.05$, see Table 3 ). Collectively these terms explained $85 \%$ and $83 \%$ of the total variance in mass loss after 7 and 14 months respectively. The significant variables are now described in more detail, starting with those factors with the greatest explanatory power.

Species identity had by far the strongest influence on decomposition rate (Table 3; Fig. 2a, b). When averaged across all replicates and forest types, litter decomposition rates differed more than two-fold among species. Only $30 \%$ of D. cuppressinum litter and $36 \%$ of $M$. umbellata litter had been lost after 14 months, compared with a loss of $66 \%$ of $G$. littoralis and $63 \%$ of $P$. simplex litter. The litter mass loss of the other species was in between these extremes.

Only lignin content correlated significantly with \% litter mass loss ( 7 months, $r=-0.74, P=0.04 ; 14$ months, $r=-0.74, P=0.03)$. Thus, species containing greater concentrations of lignin were slower to decompose. Neither the concentrations of $\mathrm{N}$ or $\mathrm{P}$ in the leaf litter, nor the concentrations of secondary compounds other than lignin had any discernable effect on decomposition rate $(P>0.20$ in all cases). There was much greater variability among species in the first period (17-58\% compared with 14-25\%; see Fig. 2a). This suggests that much of the easily decomposable material was lost during the first 7 months from the less-lignified species, whereas in the second period the remaining tissues were similarly recalcitrant across all species. Decomposition rates in the first and second periods were uncorrelated ( $r=0.17, P=0.96)$.

Table 3 ANOVA indicating the statistical significance of factors that influence decomposition of leaf litter in litter mixtures

\begin{tabular}{|c|c|c|c|c|c|c|c|c|c|}
\hline & \multirow[t]{2}{*}{$d f$} & \multicolumn{4}{|c|}{ After 7 months of incubation } & \multicolumn{4}{|c|}{ After 14 months of incubation } \\
\hline & & MS & $F$ & $P$ & $r^{2}$ & MS & $F$ & $P$ & $r^{2}$ \\
\hline Species (S) & 7 & 25,028 & $\mathbf{1 , 0 0 2 . 3}$ & $<0.00001$ & 0.860 & 20,321 & 481.2 & $<0.0001$ & 0.670 \\
\hline Forest type $(F)$ & 1 & 3,650 & 146.1 & $<0.00001$ & 0.018 & 19,851 & 470.1 & $<0.0001$ & 0.094 \\
\hline Other species $(\mathrm{O})$ & 7 & 41 & 1.6 & 0.1203 & 0.001 & 231 & 5.5 & $<0.0001$ & 0.008 \\
\hline $\mathrm{S} \times \mathrm{F}$ & 7 & 25 & 1.0 & 0.4283 & 0.001 & 131 & 3.1 & 0.003 & 0.004 \\
\hline $\mathrm{S} \times \mathrm{O}$ & 49 & 31 & 1.2 & 0.1370 & 0.007 & 54 & 1.3 & 0.099 & 0.012 \\
\hline $\mathrm{O} \times \mathrm{F}$ & 7 & 33 & 1.3 & 0.2460 & 0.001 & 55 & 1.3 & 0.25 & 0.002 \\
\hline $\mathrm{S} \times \mathrm{O} \times \mathrm{F}$ & 49 & 32 & 1.2 & 0.0921 & 0.008 & 48 & 1.1 & 0.25 & 0.011 \\
\hline Blocking term & 14 & 69 & 2.76 & 0.0005 & 0.005 & 428 & 10.1 & $<0.0001$ & 0.028 \\
\hline Residuals $^{\mathrm{a}}$ & $808 / 858$ & 25 & & & & 42 & & & \\
\hline
\end{tabular}

The explanatory variables were the identity of the species measured (Species), the forest type (Forest), the identity of the other species in the mixture (Other species), and a blocking term reflecting the hierarchical sampling design. Statistically significant effects are shown in bold. The relative importance of a factor is expressed as its sum of squares as a proportion of the total sum of squares $\left(r^{2}\right)$

${ }^{a}$ Different $d f$ for the two incubation periods because the numbers of bags not recovered from the field differed between collections 
The second strongest influence on decomposition rate, after species identity, was the forest type in which the bags were incubated (Table 3). The influence of forest type was much smaller than the effect of species: by the end of the first incubation period the mean litter loss on the alluvial and terrace sites differed by only $3.9 \%$ but by the end of the second period this difference had risen to $10.3 \%$. Consistently slower decomposition rates were observed in the nutrient-poor site than in the nutrient-rich site for all species (Fig. 2b). There was significant variation among species in their response to forest type by 14 months of incubation (the Species $\times$ Forest interaction in Table 3) but these differences in response did not relate to any of the litter traits we measured.

The least important influence on decomposition rate was the identity of the other species in the mixture (Table 3 ). The effects of the other species were relatively small, shifting the percent biomass loss by no more than $1.5 \%$ on average over 14 months (Fig. 2c). However, the error bars in this figure are relatively large, indicating that the effects of neighbour species can be larger in individual cases. There was no evidence of significant specific pairwise interactions among species (shown by the non significant Species $\times$ Other species effect; Table 3 ). Rather, a species either accelerated or decelerated decomposition of the other species with which it was mixed at a rate that was irrespective of the other species' identity. This is illustrated for instance by both $G$. littoralis and $P$. simplex, the species that decomposed significantly faster in single-species litter bags than all the other species (Fig. 2). After 7 months of incubation at the alluvial site, G. littoralis litter did not accelerate the decomposition of the other species it was mixed with (except $W$. racemosa; data not shown). Instead, $G$. littoralis litter itself decomposed faster when mixed with most of the other litter types. P. simplex, the other fast decomposing species, contrary to expectation, did not accelerate the decomposition of any of its neighbour species either, but decreased the mass loss of both $P$. colorata and $N$. menziesii litter. There were less interactions after 7 months in the marine terrace forest: only the two podocarp species decomposed significantly slower than expected when both were mixed with M. umbellata. After 14 months of incubation there were only significant positive interactions (higher mass loss) at both the alluvial and intermediate forests, except for a negative effect of $P$. hallii on mass loss of $D$. cupressinum. In both forest types $G$. littoralis showed a similar, albeit less pronounced, pattern as at the alluvial site after 7 months, i.e. more mass loss than expected when mixed with many of the other species. Additionally, after 14 months of incubation $P$. simplex showed a more or less similar pattern to G. littoralis in both forest types. Furthermore, W. racemosa litter lost more mass when mixed with $N$. menziesii.
Thus, there is some evidence that species that accelerated the decomposition rate of other species were those that decomposed slowly themselves, whereas species that decelerated the decomposition rate tended to have an inherently fast rate of decomposition. This relationship was found to be significant on the terrace sites, but not on the alluvial sites (Fig. 3). However, the absolute effects were very small.

\section{Discussion}

Species identity, litter quality and litter decomposition

As we separated the individual species in the mixtures and used a new statistical analysis technique, we were able to demonstrate quantitatively that species identity was by far the strongest determinant of leaf litter decomposition rate compared to the other factors that we investigated (Table 3). Although a very large part of the species-specific differences in litter decomposition rate could be explained by interspecific differences in initial litter lignin concentration, this implies that species identity also contains a significant amount of unique information (cf. Dorrepaal et al. 2005; Cornwell et al. 2008). Species identity encompasses a wide array of not only chemical characteristics of the litter (e.g. initial litter C, N, P, phenolics, lignin concentration), but also physical litter characteristics (e.g. toughness, structure, wax layers) that do not necessarily correlate with

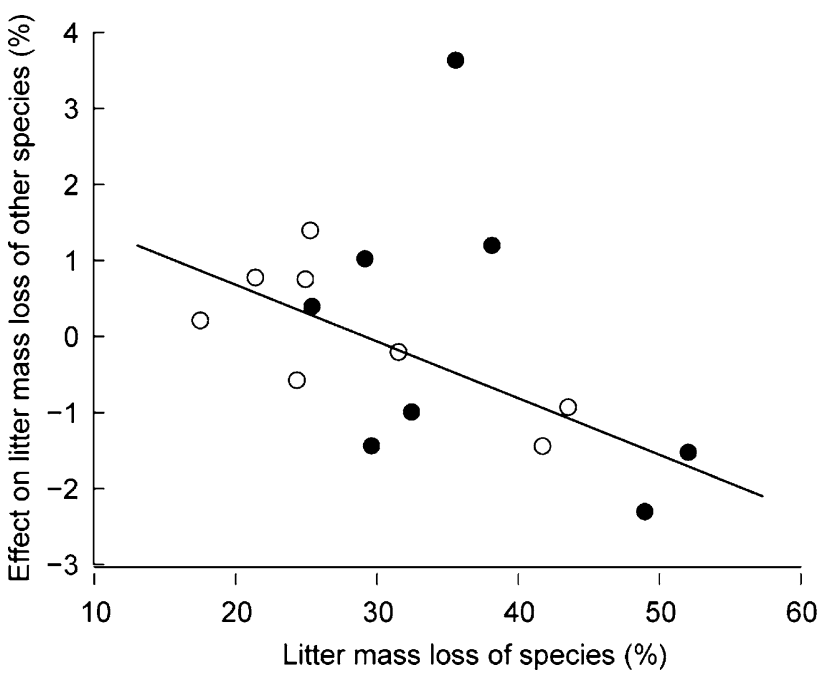

Fig. 3 Relationship between the \% litter loss in the period 0-14 months of incubation for eight New Zealand tree species, and the influence that the species has on the decomposition of other species when placed in a mixture with them (filled circles denote alluvial sites, $r=-0.39, P=0.33$; open circles denote terrace sites, $r=-0.73$, $P=0.04$, with regression line shown; MA regression; Warton et al. 2006)). Positive numbers on the $y$-axis correspond with accelerated loss rates 
each other. The rate at which litter is broken down might be influenced by several of these parameters simultaneously and each species has a unique combination of all the traits that determine litter decomposition. Therefore, it is not surprising that focusing on one or a few litter chemistry parameters does not always result in a good correlation with litter decomposability. In our study, however, interspecific differences in a single litter chemistry parameter could explain a very large part of the interspecific differences in litter mass loss, which is comparable to results from e.g. Melillo et al. (1982), Hobbie (1996) and Aerts et al. (2003).

Over the entire duration of our study, interspecific differences in litter mass loss were strongly correlated with initial litter lignin concentration. This is somewhat contrary to the widely accepted view that initial litter nutrient concentration is the main factor regulating litter decomposition, especially during the initial stages (cf. Aerts 1997). For example, Berg and Staaf (1980) found that initial litter nutrient concentration correlated with mass loss during the earlier stages of decomposition, whereas litter lignin concentration was important in the later stages. Hobbie and Vitousek (2000) argue that the fact that numerous studies showed little to no effect of $\mathrm{N}$ fertilisation on decomposition suggests that limitation by $\mathrm{C}$ quality instead of nutrients may occur much more frequently than commonly assumed. This is further illustrated in a study by Hobbie (2000), where she found that in an Hawaiian montane forest, $\mathrm{N}$ fertilisation increased the decomposition of litter containing a low proportion of lignin $(<12 \%$ lignin) in Metrosideros polymorpha litter, more than that with a high proportion of lignin ( $>18 \%$ lignin). From these results, it was concluded that decomposers were limited by substrate $\mathrm{C}$ quality. The initial lignin concentration of the litter in our study mostly ranges from 12 to $24 \%$. Therefore, it is likely that decomposers may have been limited by the poor $\mathrm{C}$ quality of the litter in our study.

\section{Forest type}

Average litter mass loss was higher on the younger, more fertile alluvial soils than on the older, less fertile marine terrace soils. Similar results have been reported for a number of chronosequences, where litter decomposition rate also declined with increasing soil age and decreasing soil fertility (Crews et al. 1995; Hobbie and Vitousek 2000; Wardle et al. 2004; Jonsson and Wardle 2008). This is most likely driven by differences in the activity and composition of the decomposer community at the different terraces. Other studies at the Waitutu marine terrace sequence found that, with increasing soil age (expressed on a soil $\mathrm{C}$ basis), there was a decline in microbial biomass and activity as well as a shift from bacterial- to fungal-based soil food webs
(Williamson et al. 2005). A smaller and less active microbial community could account for the observed decline in litter decomposition rate. Additionally, a shift towards fungal-based soil food webs with increasing soil age results in increasingly closed and more retentive nutrients cycles (Williamson et al. 2005; Jonsson and Wardle 2008), which might contribute to a lower litter decomposition rate.

\section{Decomposition in litter mixtures}

Litter-mixture effects were the third most significant factor influencing litter mass loss in our study. However, these effects were relatively small, and only shifted percentage mass loss over 14 months within the range of $1.5 \%$ compared to the expected mass loss based upon decomposition of monospecific litter. Thus, additive effects predominate in this ecosystem, so that mass dynamics of the mixtures can largely be predicted from the monocultures. A similar result was found by Ball et al. (2008) in a litter bag study with leaves of four deciduous tree species.

It has been proposed that litter-mixture effects are caused by differences in litter quality between the component species of a mixture or by effects on the micro-environment, notably moisture availability (Hector et al. 2000; Wardle et al. 2003; Hoorens et al. 2003; Schimel and Hättenschwiler 2007). As moisture is in ample supply in the rain forest system that we studied, we will concentrate on the chemical components of possible mixture effects. These chemical effects might be caused by the fact that resources from one litter type prime the microbial community to break down more recalcitrant litter, or inhibiting compounds from one litter type slow down the decomposition of the entire mixture (see e.g. Hättenschwiler et al. 2005). If these mechanisms are indeed responsible for litter-mixture effects (but see Hoorens et al. 2003) the relatively weak litter-mixture effects in our study might be explained by the fact that litter mass loss was strongly correlated with initial litter lignin concentration instead of initial litter nutrient content.

As we used only two-species mixtures in this study and as we were able to quantify the neighbour effects directly by separating the species, we can identify which chemical factors might play a role in these interactions. We found that the interactions were most frequent at the alluvial site, which supports the findings of Jonsson and Wardle (2008) that litter interactions depend on the biotic and abiotic characteristics of an ecosystem. The litters that we used varied widely in their chemical constituents (Table 2). Thus, there was a significant potential for chemical interactions among different species (cf. Hoorens et al. 2003; Schimel and Hättenschwiler 2007). Nevertheless, such interactions hardly seemed to occur and if so, the overall effect was very weak. However, the large error bars in Fig. 2c already show that there was high interspecific variation in the neighbour 
effects. This is further substantiated by the analyses shown in Fig. 3. It appears that only a few neighbour species had a statistically significant effect on decomposition of the 'target' species, as supported by the lack of a significant Species $\times$ Other species interaction. However, we found that when a relatively fast-decomposing species was added, this generally slowed down the decomposition of a mixture. This is in disagreement with Hättenschwiler and Gasser (2005), who stated that decomposition of relatively recalcitrant species is accelerated when other species are present, but accompanying species are of limited importance for changing the mass loss of more rapidly decomposing species.

What might be the cause of these unexpected patterns? The crucial species here are G. littoralis and P. simplex, both fast decomposing large-leaved angiosperms (Fig. 2a). Both species have a low total concentration of structural compounds (cellulose, lignin, total phenols; Table 2), but not the highest $\mathrm{N}$ concentrations of the eight species that we studied. Contrary to expectation, based on the decomposition rates, Griselinia litter did not accelerate the decomposition of the other species it was mixed with (except $W$. racemosa). Instead, Griselinia litter itself decomposed faster when mixed with most of the other litter types. Contrary to expectation, Pseudopanax did not accelerate the decomposition of any of its neighbour species, but actually decreased the mass loss of both P. colorata and N. menziesii litter.

A clue to these unexpected results might be that singlespecies decomposition rates were not related to initial nutrient ( $\mathrm{N}$ and/or $\mathrm{P}$ ) concentrations, but to the lignin content, where the fastest decomposing species (G. littoralis and P. simplex) had the lowest lignin content. For Griselinia it seems that the decomposition of this relatively low-N species increased when it decomposes with a high-N neighbour, such as $D$. cupressinum (Table 2). This supports the idea that high-N species speed up the decomposition of low-N species in the mixture by transferring $\mathrm{N}$ to the low-N species (cf. Schimel and Hättenschwiler 2007). However, Griselinia also decomposed faster when mixed with $P$. colorata, an extremely low-N species (Table 2). It should be noted, however, that this species has a very high $\mathrm{P}$ concentration and thus might alleviate possible $\mathrm{P}$ limitation of decomposition as indicated by the very high N/P mass ratios in the litters (higher than 20 in all species, except Pseudowintera). Nevertheless, it should be emphasized that the decomposition rates of the single-species mixtures are not correlated with initial $\mathrm{N}$ or $\mathrm{P}$ concentrations, so it is questionable if these explanations are correct. The other fast-decomposing species, Pseudopanax, decreased the mass loss of both $P$. colorata and $N$. menziesii litter. This could not have been caused by inhibiting compounds in Pseudopanax litter, as both its lignin and its phenolics concentrations are at the low end of the values found in this study (Table 2). Such inhibiting effects do not seem to play an important role anyway, as we only found a negative effect of the presence of $M$. umbellata on two species in the mixtures, whereas $W$. racemosa, the other species with a very high phenolics concentrations, had no negative effects on the decomposition of the other species. In addition, for both species even a positive effect on the decomposition of G. littoralis was observed.

\section{Conclusion}

Separating the components of the mixed-species litterbags and combining this with a new statistical approach allowed us to quantify the importance of litter-mixing effects and neighbour identity, relative to the effects of species identity, litter chemistry and litter incubation environment. We showed that species identity, litter chemistry and forest type are the most important drivers of litter decomposition in a New Zealand rain forest, and that neighbour identity and litter-mixture effects-although statistically significant-are far less important. This implies that additive effects predominate in this ecosystem, so that mass dynamics of the mixtures can be predicted from the monocultures. The mixture effects are more prominent in a fertile site than in an unfertile site (cf. Jonsson and Wardle 2008). Our findings further support the idea that litter-mixing effects tend to be idiosyncratic due to the importance of effects of individual species in the mixture. We succeeded in quantifying the neighbour effects and showed that they can not be explained by their chemical characteristics.

Acknowledgments The authors would like to thank the Waitutu Incorporation for permission to work on privately owned land, and the Department of Conservation for their logistical support. We would further like to thank the many people who helped collect leaf litter, Martin Stroetenga and Marjon Krutzen for help with cleaning and sorting litter, and Laura Fagan for help. This research would not have been possible without the financial support of the Netherlands Organization for Scientific Research (NWO; grant no. R84-511) and Landcare Research, New Zealand.

Open Access This article is distributed under the terms of the Creative Commons Attribution Noncommercial License which permits any noncommercial use, distribution, and reproduction in any medium, provided the original author(s) and source are credited.

\section{References}

Aerts R (1997) Climate, leaf litter chemistry and leaf litter decomposition in terrestrial ecosystems: a triangular relationship. Oikos 79:439-449

Aerts R (1999) Interspecific competition in natural plant communities: mechanisms, trade-offs, and plant-soil feedbacks. J Exp Bot 50:29-37

Aerts R, de Caluwe H, Beltman B (2003) Plant community mediated vs. nutritional controls on litter decomposition rates in grasslands. Ecology 84:3198-3208 
Anderson JM, Hetherington SL (1999) Temperature, nitrogen availability and mixture effects on the decomposition of heather (Calluna vulgaris (L.) Hull) and bracken (Pteridium aquilinum (L.) Kuhn) litters. Funct Ecol 13:116-124

Ball BA, Hunter MD, Kominoski JS, Swan CM, Bradford MA (2008) Consequences of non-random species loss for decomposition dynamics: experimental evidence for additive and non-additive effects. J Ecol 96:303-313

Berg B, Staaf H (1980) Decomposition rate and chemical changes of Scots pine needle litter. II. Influence of chemical composition. Ecol Bull 32:373-390

Cadisch G, Giller KE (eds) (1997) Driven by nature. Plant litter quality and decomposition. CAB International, Wallingford

Coomes DA, Wright E, Canham CD, Forsyth D, Bentley W, Parfitt RL, Gaxiola A, Phipps E, Fagan L, Burrows L, Duncan R, Wardle DA, Choquenot D, Ruscoe WA, Wilson DJ, Allen RB (2005) The hare, the tortoise, and the crocodile: the ecology of angiosperm dominance, conifer persistence, and fern filtering. J Ecol 93:918-935

Cornwell WK, Cornelissen JHC, Amatangelo K, Dorrepaal E, Eviner VT, Godoy O, Hobbie SE, Hoorens B, Kurokaw H, Perez Harguindeguy $\mathrm{H}$, Quested HM, Santiago LS, Wardle DA, Wright IJ, Aerts R, Allison S, van Bodegom PM, Brovkin V, Chatain A, Callaghan TV, Diaz S, Garnier E, Gurvich DE, Kazakou E, Klein J, Read J, Reich PB, Soudzilovskaia NA, Vaieretti MV, Westoby M (2008) Plant species traits are the predominant control on litter decomposition rates within biomes worldwide. Ecol Lett 11:1065-1071

Crews TE, Kitayama K, Fownes JH, Riley RH, Herbert DA, MuellerDombois D, Vitousek PM (1995) Changes in soil phosphorous fractions and ecosystem dynamics across a long chronosequence in Hawaii. Ecology 76:1407-1424

Dent DH, Bagchi R, Robinson D, Majalap-Lee N, Burslem DFRP (2006) Nutrient fluxes via litterfall and leaf litter decomposition vary across a gradient of soil nutrient supply in a lowland tropical rain forest. Plant Soil 288:197-215

Dorrepaal E, Cornelissen JHC, Aerts R, Wallén B, van Logtestijn RSP (2005) Are growth forms consistent predictors of leaf litter quality and decomposability across peatlands along a latitudinal gradient? J Ecol 93:817-828

Gartner TB, Cardon ZG (2004) Decomposition dynamics in mixedspecies leaf litter. Oikos 104:230-246

Grime JP, Cornelissen JHC, Thompson K, Hodgson JG (1996) Evidence of a causal connection between anti-herbivore defence and the decomposition rate of leaves. Oikos 77:489-494

Hättenschwiler S, Gasser P (2005) Soil animals alter plant litter diversity effects on decomposition. Proc Natl Acad Sci USA 102:1519-1524

Hättenschwiler S, Vitousek PM (2000) The role of polyphenols in terrestrial ecosystem nutrient cycling. Trends Ecol Evol 15:238-243

Hättenschwiler S, Tiunov AV, Scheu S (2005) Biodiversity and litter decomposition in terrestrial ecosystems. Annu Rev Ecol Evol Syst 36:191-218

Hector A, Beale AJ, Minns A, Otway SJ, Lawton JH (2000) Consequences of the reduction of plant diversity for litter decomposition: effects through litter quality and microenvironment. Oikos 90:357-371

Hobbie SE (1996) Temperature and plant species control over litter decomposition in Alaskan tundra. Ecol Monogr 66:503-522

Hobbie SE (2000) Interactions between litter lignin and soil nitrogen availability during leaf litter decomposition in a Hawaiian montane forest. Ecosystems 3:484-494

Hobbie SE, Vitousek PM (2000) Nutrient limitation of decomposition in Hawaiian forests. Ecology 81:1867-1877

Hoorens B, Aerts R, Stroetenga M (2003) Does initial litter chemistry explain litter mixture effects on decomposition? Oecologia 137:578-586
Jonsson M, Wardle DA (2008) Context dependency of litter-mixing effects on decomposition and nutrient release across a long-term chronosequence. Oikos 117:1674-1682

Madritch MD, Cardinale BJ (2007) Impacts of tree species diversity on litter decomposition in northern temperate forests of Wisconsin, USA: a multi-site experiment along a latitudinal gradient. Plant Soil 292:147-159

Makkar HPS (1994) Quantification of tannins-a laboratory manual. Pasture, forage and livestock program. International Center for Agricultural Research in the Dry Areas, Syria

Mark AF, Grealish G, Ward CM, Wilson JB (1988) Ecological studies of a marine terrace sequence in the Waitutu Ecological District of southern New Zealand. Part 1. The vegetation and soil patterns. J R Soc N Z 18:29-58

McTiernan KB, Ineson P, Coward PA (1997) Respiration and nutrient release from tree leaf litter mixtures. Oikos 78:527-538

Melillo JM, Aber JD, Muratore JF (1982) Nitrogen and lignin control of hardwood leaf litter decomposition dynamics. Ecology 63:621-626

Montagnini F, Ramstad K, Sancho F (1993) Litterfall, litter decomposition and the use of mulch of four indigenous tree species in the Atlantic lowlands of Costa Rica. Agrofor Syst 23:39-61

Murphy J, Riley JP (1962) A modified single solution method for the determination of phosphate in natural waters. Anal Chim Acta 27:31-36

Ostertag R, Hobbie SE (1999) Early stages of root and leaf decomposition in Hawaiian forests: effects of nutrient availability. Oecologia 121:564-573

Parton WP, Silver WL, Burke IC, Grassens L, Harmon ME, Currie WS, King JY, Adair EC, Brandt LA, Hart SC, Fasth B (2007) Global-scale similarities in nitrogen release patterns during longterm decomposition. Science 315:361-364

Porter LJ, Hrstich LN, Chan BG (1986) The conversion of procyanidins and prodelphinidins to cyanidin and delphinidin. Phytochemistry $25: 223-230$

Quested HM, Press MC, Callaghan TV, Cornelissen JHC (2002) The hemiparasitic angiosperm Bartsia alpina has the potential to accelerate decomposition in sub-arctic communities. Oecologia 130:88-95

Richardson SJ, Peltzer DA, Allen RB, McGlone MS (2005) Resorption proficiency along a chronosequences: responses among communities and within species. Ecology 86:20-25

Robinson CH, Kirkham JB, Littlewood R (1999) Decomposition of root mixtures from high arctic plants: a microcosm study. Soil Biol Biochem 31:1101-1108

Rowland AP, Roberts JD (1994) Lignin and cellulose fractionation in decomposition studies using acid-detergent fiber methods. Commun Soil Sci Plan 25:269-277

Schimel JP, Hättenschwiler S (2007) Nitrogen transfer between decomposing leaves of different $\mathrm{N}$ status. Soil Biol Biochem 39:1428-1436

Schimel JP, Cates RG, Ruess R (1998) The role of balsam poplar secondary chemicals in controlling soil nutrient dynamics through succession in the Alaskan taiga. Biogeochemistry 42:221-234

Swift MJ, Heal OW, Anderson JM (1979) Decomposition processes in terrestrial ecosystems. Studies in ecology, vol 5. University of California Press, Berkeley

Tenney FG, Waksman SA (1929) Composition of natural organic materials and their decomposition in the soil. IV. The nature and rapidity of decompositions of the various organic complexes in different plant materials under aerobic conditions. Soil Sci 28:5584

Ward CM (1988) Marine terraces of the Waitutu district and their relation to the late Cenozoic tectonics of the southern Fiordland region, New Zealand. J R Soc N Z 18:1-28 
Wardle DA, Bonner KI, Nicholson KS (1997) Biodiversity and plant litter: experimental evidence which does not support the view that enhanced species richness improves ecosystem function. Oikos 79:247-258

Wardle DA, Nilsson M-C, Zackrisson O, Gallet C (2003) Determinants of litter mixing effects in a Swedish boreal forest. Soil Biol Biochem 35:827-835

Wardle DA, Walker LR, Bardgett RD (2004) Ecosystem properties and forest decline in contrasting long-term chronosequences. Science 305:509-513
Warton DI, Wright IJ, Falster DS, Westoby M (2006) Bivariate linefitting methods for allometry. Biol Rev 81:259-291

Waterman PG, Mole S (1994) Analysis of phenolic plant metabolites. Methods in ecology. Blackwell, London

Williamson WM, Wardle DA, Yeates GW (2005) Changes in soil microbial and nematode communities during ecosystem decline across a long-term chronosequence. Soil Biol Biochem 37:12891301 